\title{
Inappropriate Discharges of Intravenous Implantable Cardioverter Defibrillators Owing to Lead Failure
}

\author{
Takashi WashizuKA, ${ }^{1} \mathrm{MD}$, Masaomi CHInUshI, ${ }^{1} \mathrm{MD}$, Ryu KAZAMA, ${ }^{1} \mathrm{MD}$, \\ Takashi Hirono, ${ }^{1}$ MD, Hiroshi Watanabe, ${ }^{1} \mathrm{MD}$, Satoru KomurA, ${ }^{1} \mathrm{MD}$, \\ Hirotaka SugIURA, ${ }^{1}$ MD, Yasutaka TANABE, ${ }^{1} \mathrm{MD}$, Hiroshi FurUSHIMA, ${ }^{1} \mathrm{MD}$, \\ Satoru FuJita, ${ }^{1} \mathrm{MD}$, Yuji OKURA, ${ }^{1} \mathrm{MD}$, and Yoshifusa AIZAwA, ${ }^{1} \mathrm{MD}$
}

\begin{abstract}
SUMMARY
We describe here the case of a 58-year-old female patient who experienced inappropriate shocks from her implantable cardioverter-defibrillator (ICD). Stored electrograms from her ICD showed high frequency noise preceding the shock. Although the pacing threshold was normal and lead fracture was not found in chest X-rays, pacing lead impedance decreased to $480 \Omega$. Moreover, such high frequency noise was observed by electrogram telemetry, but not by routine evaluation every 3 months. ICD lead dysfunction was suspected, so we elected to replace the ICD lead system. At the time of the operation, lead impedance was $410 \Omega$ and pacing threshold was the same as it was at the time of the ICD implantation, and no lead insulation disturbances were observed in the generator pocket. However, manipulation of the lead system produced high frequency noise reproducibly. Since some of the ICD lead dysfunction initially was clinically silent at rest, dysfunction was difficult to detect before serious problems occurred. Therefore, more careful evaluation of the ICD lead system is needed during long-term follow-up of ICD implants. (Int Heart J 2005; 46: 909-913)
\end{abstract}

Key words: Implantable cardioverter defibrillator, Inappropriate shock, Lead failure

THE implantable cardioverter-defibrillator (ICD) is widely used for patients with malignant ventricular tachyarrhythmias and can prevent sudden cardiac death. ${ }^{1,2)}$ Transvenous lead systems have decreased the length of hospital stay, morbidity, and mortality in patients with ICD. However, they are imperfect and ICD lead dysfunction has been reported. ${ }^{3-7)}$ ICD lead dysfunction may result in failure of the ICD therapy for ventricular tachycardia (VT) or fibrillation (VF) and lead to syncope or sudden death. Lead dysfunction may also cause inappropriate shocks and subsequent psychological distress. In addition, some of the lead dysfunction initially is clinically silent, so it is difficult to find lead dysfunction

From the ${ }^{1}$ Division of Cardiology, Niigata University Graduate School of Medical and Dental Sciences, Niigata, Japan.

Address for correspondence: Takashi Washizuka, MD, Division of Cardiology, Niigata University Graduate School of Medical and Dental Sciences, Asahimachi 1-754, Niigata 951-8510, Japan.

Received for publication February 2, 2005.

Revised and accepted July 4, 2005. 
before serious problems occur. Thus, ICD lead dysfunction is one of the most important problems in patients with ICD. Nevertheless, reports of ICD lead dysfunction are rare in Japan. We report here a case of inappropriate shocks caused by oversensing due to ICD lead dysfunction.

\section{CASE REPORT}

The patient was a 58-year-old female who suffered a myocardial infarction in 1994. In February 1997, she had near syncope and sustained VT at a rate of 210 bpm. At electrophysiological study, 5 morphologically distinct monomorphic VTs including clinical VT were induced, and they were still inducible after administration of procainamide, flecainide, or amiodarone. In April 1997, a transvenous ICD system (Medtronic Micro Jewel, 7223, model 6936 right ventricular screw-in lead, Medtronic Inc., Minneapolis, MN, USA) was implanted through the cephalic vein. At the operation, shocks at $20 \mathrm{~J}$ were twice confirmed to be capable of terminating VF induced by T-wave shocks, and delivery of $5 \mathrm{~J}$ was set as the first treatment of VT and $30 \mathrm{~J}$ was set as the first treatment of VF. The amplitude of the ventricular electrogram from the tips of the defibrillation lead was $8.2 \mathrm{mV}$ during sinus rhythm and the pacing threshold at the site was $4.0 \mathrm{~V}$ at a pulse width of $0.20 \mathrm{msec}$ with an impedance of $809 \Omega$. In October 1997, she

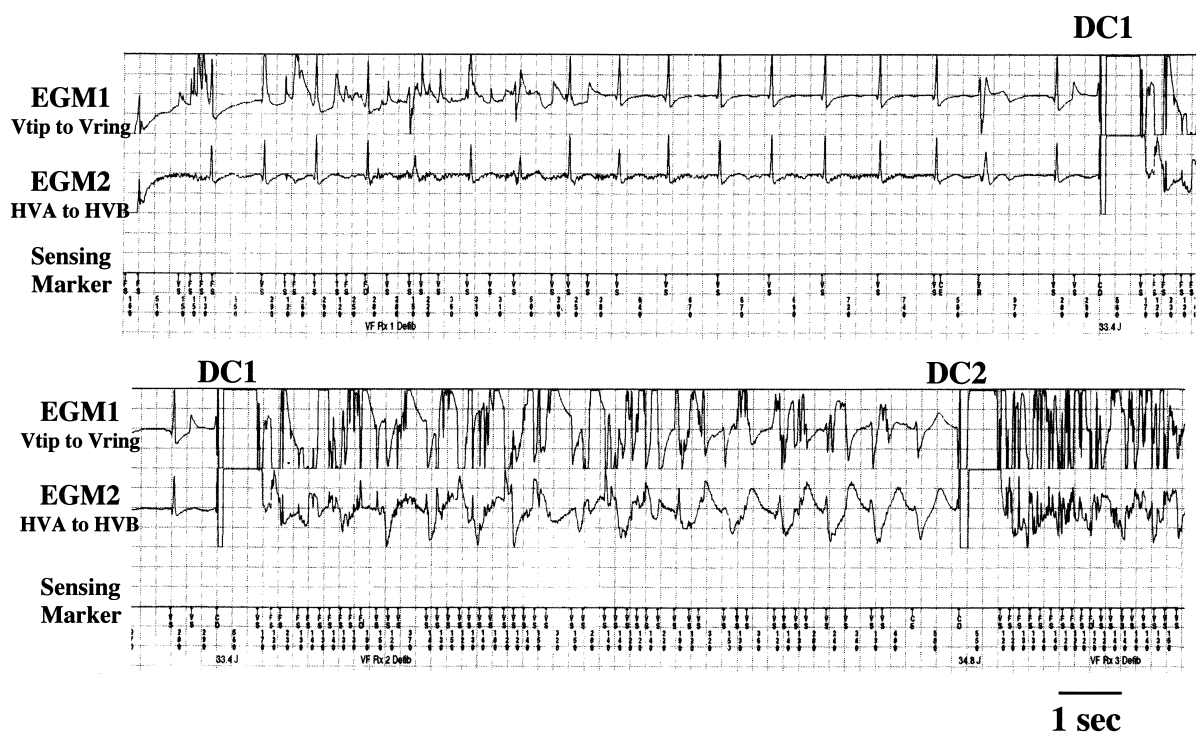

Figure 1. Stored electrocardiogram recordings on admission.

Intracardiac electrograms 1 (Vtip to Vring) showed high frequency noise during sinus rhythm. The patient received an inappropriate shock in response to oversensing (DC1), then received a total of 4 inappropriate shocks in response to oversensing. EGM $=$ intracardiac electrograms. 


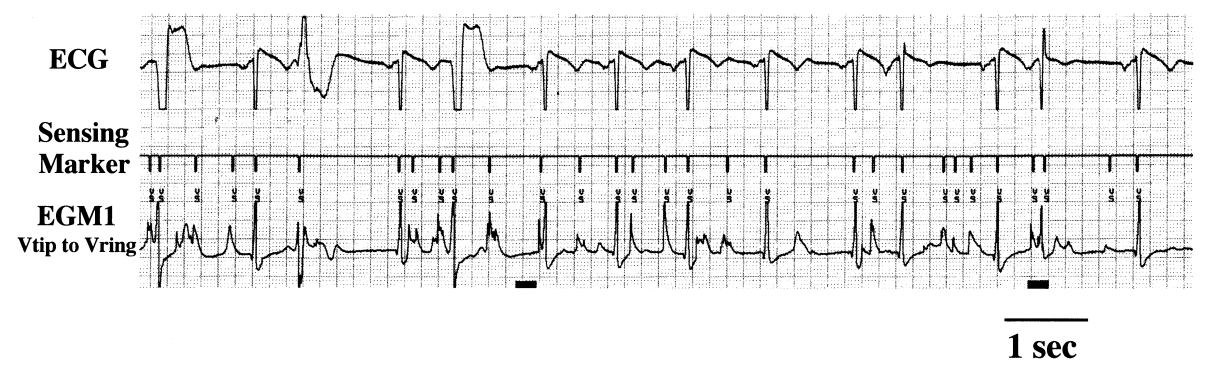

Figure 2. Real-time telemetered intracardiac electrogram recordings.

High frequency noise seen in intracardiac electrograms (Vtip to Vring) is not observed in surface electrocardiograms.

experienced one spontaneous shock and VT was successfully detected and terminated by the device. In January 2001, the device had reached its elective replacement indicator, a charge time of 20 seconds. In February 2001, the device was replaced by a GEM ICD $(7227 \mathrm{Cx}$, Medtronic Inc.). At the time of the operation, the pacing threshold was $4.0 \mathrm{~V}$ at a pulse width of $0.50 \mathrm{msec}$ with an impedance of $694 \Omega$, so the lead system was not changed. Shocks at 25 J were twice confirmed to be capable of terminating VF induced by T-wave shock. After the operation, a routine evaluation every 3 months at our out-patient ICD clinic revealed no spontaneous shock, and the pacing threshold and amplitude of the sensed $\mathrm{R}$ wave did not change. In November 2002, she experienced several shocks during sitting. Interrogation of the device revealed 4 shocks of $35 \mathrm{~J}$, and retrieval of the stored electrogram showed that high frequency noise preceded the shock (Figure 1). Although the pacing threshold did not change and lead fracture was not obvious in chest X-rays, the pacing lead impedance decreased to $480 \Omega$. Moreover, such high frequency noise was observed on the electrogram telemeter (Figure 2). Since dysfunction of the sensing lead was suspected, we elected to implant a new lead system. At the time of the operation, lead impedance was $410 \Omega$ and pacing threshold did not change, and no lead insulation disturbances were observed in the generator pocket. However, manipulation of the lead system produced high frequency noise reproducibly. Thus, we implanted a new ICD lead system (Medtronic model 6943 right ventricular screw-in lead). Using the new lead system, the pacing threshold was $0.5 \mathrm{~V}$ at a pulse width of $0.50 \mathrm{msec}$ with an impedance of $1339 \Omega$, and the amplitude of the ventricular electrogram from the tips of the defibrillation lead was $9.0 \mathrm{mV}$ during sinus rhythm. Although we attempted to extract the old lead system, it could not be extracted because of adhesion to the vessel wall. Therefore, we were unable to determine the exact site of lead failure. After the operation, neither inappropriate discharge nor high frequency noise was observed by telemetry during the ensuing 6 months. 


\section{DISCUSSION}

In this patient, oversensing of high frequency noise was observed and it caused inappropriate shocks. Lead dysfunction was suspected as the cause of oversensing since the lead impedance decreased and high frequency noise was observed by electrogram telemetry in real time, although the site of lead fracture was undetermined on the chest X-rays or during ICD lead replacement.

Lead failure is one of the most serious complications of defibrillator systems since it may result in sudden cardiac death if VT or VF is not detected or not terminated by the ICD. In addition, lead problems often result in oversensing and inappropriate shocks. The relatively high failure rate of ICD leads has been recently reported by others, including the manufacturer. ${ }^{5-9)}$ Luria, et $a l^{5)}$ and Hauser, et $a l^{6)}$ have both reported failure rates for the ICD lead of close to $20 \%$ at four years. More recently, Ellenbogen, $e t a l^{7)}$ reported that the failure probability of the polyurethane lead, which is the same as the lead that failed in our patient, was $37 \%$ after a mean follow-up period of 68.6 months. The subclavian crush syndrome, which was caused by compression of a lead between the first rib and clavicle, has been reported as one of the major causes of lead failure in pacemakers and ICDs. In previous reports, it occurred in 0.9-1.8\% of ICD patients, ${ }^{10,11)}$ and the occurrence of subclavian crush syndrome increases significantly when subclavian venipuncture was performed compared to cephalic venous cutdown at lead insertion. In this case, lead insertion was performed by cephalic venous cutdown, so it would not seem that subclavian crush syndrome was the cause of the lead failure.

The main consequence of lead failure found in all studies was oversensing, as we found in this case. The manufacturer's ${ }^{8)}$ analysis also showed that the polyurethane lead is vulnerable to structural damage. The outer and middle insulation layers and the high voltage coil account for $79 \%$ of the confirmed defects. This finding suggests that the $80 \mathrm{~A}$ polyurethane insulation is the cause of low lead durability. However, routine follow-up may not detect some lead failures because 1) the defect is partial and therefore the lead problems may be intermittent, and 2) routine follow-up (usually every 3 months) may be insufficient. As previously reported, ${ }^{9)}$ ICD lead insulation failure was usually associated with normal values for impedance, sensing and pacing threshold at the time of lead failure. To detect these insulation failures, Dorwarth, et $a l^{9)}$ showed the importance of short RR interval $(<140 \mathrm{msec})$ nonsustained VT in stored intracardiac electrograms. They reported that 31 of 261 ICD patients experienced a lead related sensing failure during a mean follow-up period of $4.0 \pm 2.6$ years, and in 21 of 31 patients device interrogation showed short RR interval nonsustained VT $40 \pm 43$ days before clinically relevant lead failure. Therefore, if short RR interval nonsustained VT is 
recorded at routine ICD follow-up, the device system should be checked more carefully. Moreover, because the survival rate of polyurethane leads decreases 4 years after implantation, routine follow-up should be performed every month in these patients, although reports of ICD lead failure are rare in our country.

In conclusion, we have described a case of inappropriate shocks due to lead failure. In ICD patients who have polyurethane leads, more frequent evaluation of the ICD lead system is needed.

\section{REFERENCES}

1. AVID investigators. A comparison of antiarrhythmic-drug therapy with implantable defibrillators in patients resuscitated from near-fatal ventricular arrhythmias. The Antiarrhythmics versus Implantable Defibrillators (AVID) Investigators. N Engl J Med 1997; 337: 1576-83.

2. Buxton AE, Lee KL, Fisher JD, Josephson ME, Prystowsky EN, Hafley G. A randomized study of the prevention of sudden death in patients with coronary artery disease. Multicenter Unsustained Tachycardia Trial Investigators. N Engl J Med 1999; 341: 1882-90.

3. Lawton JS, Wood MA, Gilligan DM, Stambler BS, Damiano RJ Jr, Ellenbogen KA. Implantable transvenous cardioverter defibrillator leads: the dark side. Pacing Clin Electrophysiol 1996; 19: 1273-8. (Review)

4. Degeratu FT, Khalighi K, Peters RW, Shorofsky SR, Gold MR. Sensing lead failure in implantable defibrillators: a comparison of two commonly used leads. J Cardiovasc Electrophysiol 2000; 11: 21-4.

5. Luria D, Glikson M, Brady PA, et al. Predictors and mode of detection of transvenous lead malfunction in implantable defibrillators. Am J Cardiol 2001; 87: 901-4.

6. Hauser RG, Cannom D, Hayes DL, et al. Long-term structural failure of coaxial polyurethane implantable cardioverter defibrillator leads. Pacing Clin Electrophysiol 2002; 25: 879-82.

7. Ellenbogen KA, Wood MA, Shepard RK, et al. Detection and management of an implantable cardioverter defibrillator lead failure: incidence and clinical implications. J Am Coll Cardiol 2003; 41: 73-80.

8. Medtronic Inc. ICD Lead Survival Analysis. Tachyarrhythmia Product Performance Report. 2nd ed. Fridley, MN: Medtronic; 2001.

9. Dorwarth U, Frey B, Dugas M, et al. Transvenous defibrillation leads: high incidence of failure during longterm follow-up. J Cardiovasc Electrophysiol 2003; 14: 38-43.

10. Roelke M, O'Nunain SS, Osswald S, Garan H, Harthorne JW, Ruskin JN. Subclavian crush syndrome complicating transvenous cardioverter defibrillator systems. Pacing Clin Electrophysiol 1995: 18: 973-9.

11. Antonelli D, Rosenfeld T, Freedberg NA, Palma E, Gross JN, Furman S. Insulation lead failure: is it a matter of insulation coating, venous approach, or both? Pacing Clin Electrophysiol 1998; 21: 418-21. 